\title{
The Epidemiological Implications of Deer Fly Nuisance Biting and Transmission of Loiasis in an Endemic Area in Southeastern Nigeria
}

\author{
Emmanuel Chukwunenye Uttah \\ Department of Biological Sciences, Cross River University of Technology, PMB 1123, Calabar, Cross River State, Nigeria \\ Correspondence should be addressed to Emmanuel Chukwunenye Uttah; drecuttah@yahoo.com
}

Received 2 October 2012; Accepted 18 October 2012

Academic Editors: P. E. Cattan, J. Lewsey, and C. Raynes-Greenow

Copyright (C) 2013 Emmanuel Chukwunenye Uttah. This is an open access article distributed under the Creative Commons Attribution License, which permits unrestricted use, distribution, and reproduction in any medium, provided the original work is properly cited.

\begin{abstract}
This work was aimed at determining the epidemiological implications of deer fly biting in Southeastern Nigeria and ascertaining the circadian and monthly biting pattern and the transmission potential of Chrysops in the area. Human-landing catches were carried out for 52 weeks by a catching team of four. A total of 930 female Chrysops sp. was caught; biting peaked during the months of June through August. The highest monthly biting rate (MBR) was 353 bites per person per month in July 2006. The annual biting rate (ABR) was 3,317 bites per person per year. The overall infective rate was $3.8 \%$. A total of $314 \mathrm{~L} 3 \mathrm{~s}$ was recorded with a mean of 9.8 L3s per infective Chrysops. The highest monthly transmission potential (MTP) was 389 infective bites per month observed in July 2006. The annual transmission potential (ATP) was 1,265 infective bites per person per year. Parous rate was $29.3 \%$ and was higher during dry months of October through February. The circadian biting activities showed two peaks: between 07:00 and 10:00 hours and between 15:00 and 17:00 hours. The epidemiological implications of deer fly biting in the area are multifaceted. Resources must not be spared in bringing an end to their menace.
\end{abstract}

\section{Introduction}

Loiasis is a globally important human filarial infection found in tropical rainforest Africa afflicting about 13 million persons [1]. It is caused by a Nematode Loa loa and transmitted by Chrysops. Visitors to Loiasis endemic areas tend to be symptomatic, with a predominance of "allergic symptoms," including pruritus, urticaria, and transient, migratory angioedema, or Calabar swellings, whereas majority of infected people from endemic areas are asymptomatic despite high levels of microfilariae detectable in the peripheral blood. However, migration of the adult worm across the conjunctiva, eye worm, occurs with equal frequency in natives and visitors to endemic areas. Although this migration is often associated with a transient intense edematous conjunctivitis, most episodes resolve without sequelae. Other human filarial parasites found in Nigeria and Africa are Wuchereria bancrofti, Onchocerca volvulus, Mansonella perstans, and $M$. streptocerca $[2,3]$. L. loa infection has been recorded in
Nigeria since, at least, four decades ago [4] and has persisted in various parts of the country, especially in the rural areas. In the western part of Nigeria, L. loa microfilaraemia is prevalent and well distributed especially in the vegetational zones [58]. In the savannah zone the prevalence is relatively lower [9]. Prevalence of $L$. loa microfilaraemia between $0.7 \%$ and $5.5 \%$ has been reported [10-13].

In southeastern Nigeria, prevalence expectedly varies from one part to the other. In parts of Cross River State, $18 \%$ prevalence has been reported [14]. Earlier a prevalence value of $9.1 \%$ L. loa was reported in the Niger Delta area [15]. Similarly, L. loa was reported as part of 14 parasitic infections recorded among nomadic Fulanis of southeastern Nigeria [16]. In the Imo River Basin, the study area, Loiasis is reported to be endemic [2].

The main vectors of Loa loa in proximal eco-region are Chrysops silacea, C. dimidiata, and C. dimidiata "The Bombe form" $[17,18]$. Reported studies elsewhere do confirm that biting habits of Chrysops is influenced by deforestation, 
seasonality, and proximity to breeding sites $[19,20]$. The vagaries of Chrysops vector-environment complex is fragile and dynamic and is a function of anthropogenic land use activities. Land use is greatly affected by population size [21]. This is significant as the Loiasis endemic areas encompassing West and Central rainforest Africa are high population growth areas. There is need for regular monitoring of the unstable Chrysops-environment complex so as to ascertain possible new trends that might have implications for Loiasis epidemiology. The need for a baseline entomological data covering the biting, infection, and infectivity rates has become stronger than ever. To the best of our knowledge no work has been carried out in Nigeria on the biting activities and infection rates of Chrysops vectors. This work, therefore, aimed at determining the epidemiological implications of deer fly biting and ascertaining the circadian biting pattern, monthly biting pattern, and the transmission potential of Chrysops in the Imo River Basin, Southeastern Nigeria.

\section{Materials and Methods}

2.1. Study Area. The study was carried in the Imo River Basin (IRB), which is endemic for Loiasis, between September 2005 and August 2006. IRB lies between latitudes $4.4^{\circ}$ and $5.8^{\circ}$ North and longitudes $7.0^{\circ}$ and $7.8^{\circ}$ East. It traverses three states of Imo, Abia, and Rivers states. From the derived savannah in the upper part, it extents through the rainforest vegetation to the mangrove swamps at the Atlantic Ocean. Two neighboring communities, Umuowaibul and Ndiorji, which are located about $10 \mathrm{~km}$ northwest of Okigwe hosted the study. The two communities are socio-culturally similar and are inhabited by the Igbo tribe. Familial settlement pattern was evident in the study communities with houses arranged in family clusters.

The area is hilly with characteristic undulating plains. There are 7 streams, and three rivers in the area in addition to the Imo River, and it includes Nkpoma Stream, Ngele Asaa Stream, Aluum Stream, Ngeleocha Stream, Kirika Stream, Mpiti Stream, and Ojomoko Stream, Ibu River, Ugbi River, and Nwangele River. There are also numerous pockets of natural and man-made stagnant water pools at the banks of the rivers and streams, which are used by the villagers for processing cassava on both sides of the streams and rivers. The rivers and streams meander through forests which provide suitable breeding conditions for deer flies, the vectors of loiasis. The villagers depend on the streams and rivers for most of their water needs. Activities normally carried out in the streams or rivers include fetching water for domestic uses, swimming, bathing, and fishing. Fetched water is usually stored in drums or other plastic containers, clayey pots, and natural containers, which are normally kept under the rain tracks, most times without cover. Sanitary facilities are poor and grossly inadequate. Some families use nearby bushes for defecation, but most have acquired pit latrines.

Farming is the main occupation. Farmlands are most times in distant places, far away from residential areas, surrounded by thick forests, and provide excellent platform for man-fly contact between the villagers and biting Chrysops. The soil consists predominantly of shale, which provides good agricultural land for intense farming activities for crops like yam, cassava, maize, groundnut, vegetables, cocoyam, three-leaf yam, banana, and pineapple. The chief economic tree crops include kola nut tree, rubber tree, palm tree, oilbean tree, raffia palm tree, breadfruit tree, and local pear tree. Domestic animals include livestock such as goats, sheep, chicken, and ducks; and pets such as dogs and cats. Fishing and petty trading are also popular among men and women, respectively.

According to meteorological report from the Imo State Meteorological Service, the annual rainfall for the area averaged $2840 \mathrm{~mm}$ per annum, with most of the rainfall in the months of June through September.

2.2. Collection of Chrysops. Human-landing catches were carried out for 52 weeks from September 2005 to August 2006. The catching team of four alternated pairwise between collecting and resting. Each pair collected for one hour and rested the following hour when the other pair was collecting. They exposed their feet and legs up to the knee and deer flies were collected using aspirators. Collections started at 6:00 hours, continuing until 18:00 hours. The pairing of collectors and working hours were shifted systematically on each catching day to eliminate any possible bias that might arise from differences in each individual's attraction and catching prowess. There was a systematic shifting from one place to another in a preselected catching round. Hourly collections of Chrysops were kept separately in labeled cups, which were covered with fine nylon nets held with rubber bands. After each hourly collection, the cups with Chrysops were provided with a pad of wet cotton wool on the top and kept cool in an insulated box with cooling elements until the Chrysops could be identified and dissected. Vectors were sexed and identified based on external morphology after Oldroyd [22]. Infectivity of Chrysops was ascertained with the finding of the third stage larvae (L3) in the individual vector during dissection. Parity was determined by examination of the ovaries for tracheal distention after Hoc and Wilkes [23]. Parous mosquitoes are those that have taken a blood meal and oviposited at least once. Nulliparous mosquitoes have never oviposited.

2.3. Data Analysis. The SPSS for Windows package (1995 version) was used for entering of data and for data analysis. The annual biting rate (ABR) is an estimate of the number of deer flies coming to bite person who is exposed to biting during all biting hours of deer flies every day for one year. The annual biting rate (ABR) and the annual transmission potential (ATP) were calculated using standard criteria used in the World Health Organization Onchocerciasis Control Programme (OCP) [23].

2.4. Ethical Approval. The ethical details of the study were approved by the Ministry of Health, Okigwe Local Government Area (LGA), Imo State, Nigeria.

\section{Results}

3.1. Abundance, Seasonality, and Monthly Biting Rates of Chrysops sp. A total of 930 female Chrysops sp. was caught 
TABLE 1: Monthly entomological indices of human-landing Chrysops sp. in southeastern Nigeria.

\begin{tabular}{|c|c|c|c|c|c|c|c|c|}
\hline \multirow{2}{*}{ Month } & \multirow{2}{*}{ No. of catch days } & \multicolumn{4}{|c|}{ No. of female Chrysops } & \multirow{2}{*}{ No. L3s (L3/inf.Ch) ${ }^{\mathrm{a}}$} & \multirow{2}{*}{$\mathrm{MBR}^{\mathrm{b}}$} & \multirow{2}{*}{$\mathrm{MTP}^{\mathrm{c}}$} \\
\hline & & Collected & Dissected (\%) & Parous (\%) & Infective (\%) & & & \\
\hline September 2005 & 4 & 75 & 62 & $16(25.81)$ & $3(4.8)$ & $25(8.3)$ & 281 & 113 \\
\hline October 2005 & 4 & 71 & 66 & $23(34.8)$ & $2(3.0)$ & $23(11.5)$ & 275 & 96 \\
\hline November 2005 & 5 & 78 & 67 & $26(38.8)$ & $1(1.5)$ & $9(9.0)$ & 234 & 31 \\
\hline December 2005 & 5 & 63 & 54 & $21(38.9)$ & $0(0.0)$ & $0(0)$ & 195 & 0 \\
\hline January 2006 & 4 & 67 & 58 & $23(39.7)$ & $1(1.7)$ & $5(5.0)$ & 260 & 24 \\
\hline February 2006 & 4 & 78 & 69 & $28(40.6)$ & $2(2.6)$ & $17(8.5)$ & 273 & 67 \\
\hline March 2006 & 4 & 75 & 66 & $19(28.8)$ & $2(3.0)$ & $21(10.5)$ & 291 & 93 \\
\hline April 2006 & 4 & 78 & 76 & $18(23.7)$ & $3(3.9)$ & $29(9.7)$ & 293 & 112 \\
\hline May 2006 & 6 & 86 & 79 & $16(20.3)$ & $2(2.5)$ & $11(5.5)$ & 222 & 31 \\
\hline June 2006 & 4 & 88 & 81 & $17(21.0)$ & $4(4.9)$ & $31(7.8)$ & 330 & 126 \\
\hline July 2006 & 4 & 91 & 88 & $18(20.5)$ & $7(8.0)$ & $97(13.9)$ & 353 & 389 \\
\hline August 2006 & 4 & 80 & 78 & $22(28.2)$ & $5(6.4)$ & $46(9.2)$ & 310 & 183 \\
\hline Total & 52 & 930 & 844 & $247(29.3)$ & $32(3.8)$ & $314(9.8)$ & $3317^{b}$ & $1265^{\mathrm{e}}$ \\
\hline
\end{tabular}

L3/inf.Ch: number of L3 per infective Chrysops.

${ }^{\mathrm{b}}$ MBR: monthly biting rate an estimate of the number of a particular vector coming to bite a person who is exposed to biting during all biting hours of the vector every day for one month.

${ }^{\mathrm{c}}$ MTP: monthly transmission potential an estimate of the level of transmission of infective larvae (13) to a person during one month.

${ }^{d}$ Figure represents annual biting rate an estimate of the number of a particular vector coming to bite person who is exposed to biting during all biting hours of the vector every day for one year.

${ }^{\mathrm{e}}$ Figure represents annual transmission potential an estimate of the level of transmission of infective larvae (13) to a person during one year.

TABLE 2: The circadian activity pattern of Chrysops sp. in Southeastern Nigeria.

\begin{tabular}{lcc}
\hline Hour of collection & $\begin{array}{c}\text { No. of females } \\
\text { collected/person/hour }\end{array}$ & Percentage (\%) \\
\hline 06:00-07:00 hour & 72 & 7.8 \\
07:00-08:00 hour & 70 & 7.5 \\
08:00-09:00 hour & 92 & 9.9 \\
09:00-10:00 hour & 104 & 11.2 \\
10:00-11:00 hour & 101 & 10.9 \\
11:00-12:00 hour & 67 & 7.2 \\
12:00-13:00 hour & 56 & 6.0 \\
13:00-14:00 hour & 66 & 7.1 \\
14:00-15:00 hour & 68 & 7.3 \\
15:00-16:00 hour & 91 & 9.9 \\
16:00-17:00 hour & 86 & 9.2 \\
17:00-18:00 hour & 57 & 6.1 \\
\hline Total & 930 & 100.0 \\
\hline
\end{tabular}

by human landing catch (HLC) (see Table 1). The occurrence of biting Chrysops sp. was observed throughout the year but biting peaked during the months of June, July, and August. The monthly biting rates (MBR) of Chrysops sp. ranged from 195 bites per person per month in December 2005 to 353 bites per person per month in July 2006. The annual biting rate $(\mathrm{ABR})$ was 3,317 bites per person per year. Infective deer flies were collected in the months of September 2005 through August 2006 with the exception of December 2005 when no infective deer fly was collected. The highest infective rate was observed in the month of July 2006 . The overall infective rate for the study was 3.8\%. A total of $314 \mathrm{~L} 3 \mathrm{~s}$ was recorded in the study with a mean of $9.8 \mathrm{~L} 3 \mathrm{~s}$ per infective Chrysops. The monthly transmission potential (MTP) ranged from zero transmission in December 2005 to the highest range of 389 infective bites per month in July 2006. The annual transmission potential (ATP) was 1,265 infective bites per person per year.

3.2. Parous Rates. The overall parous rate was $29.3 \%$. It was highest in the month of February and lowest in the month of May. Parous rates were relatively and markedly higher during the dry months of October through February.

3.3. Circadian Biting Pattern of Chrysops sp. The circadian biting activity of human-landing day active Chrysops sp. is presented in Table 2. Circadian biting activities of Chrysops sp. showed two peaks: a more prolonged peak in the morning between 08:00 and 11:00 hours and a lesser prolonged peak between 15:00 and 17:00 hours in the evening. The earlier peak lasted for 3 hours and accounted for $32 \%$ of the total deer fly collections, while the lesser peak lasted for 2 hours and accounted for $19.1 \%$. The two peaks together account for $51.1 \%$ of the total deer fly bites.

\section{Discussions}

Deer flies are very abundant in the study area where they constitute public nuisance problem. The abundance was seasonal with peaks in the rainy season, but relatively stable throughout the year. Reports of higher relative abundance in the rainy season than in the dry season of vectors of other filarial species have been published [24]. The preponderance 
of permanent stagnant water bodies in the area may explain the all-year round collection of deer flies in the area. However, the number of Chrysops bites received in a particular area during a given time may not just reflect the actual abundance of Chrysops in that area, but might, in addition, be a reflection of the opportunities for contact between flies and humans [25]. The circadian pattern of Chrysops showed two peaks of biting, one in the morning and the other in late afternoon. The greatest deer fly activity normally occurs on warm, sunny days when there is little or no wind. A slight drop in temperature or a sudden breeze reduces biting attacks. Deer flies are attracted by movements, dark colours, and wood smoke [26, 27], which were rampant during these periods as villagers move to and fro their farms, fishing ports, hunting exercises, crafts, schools, and markets.

Biting by filariasis vectors correlates with distance from vector breeding site, and varies from one part of a locality to another [28]. Biting frequency is higher when one is closer to the vector breeding site and relatively lower when further away [29]. This means that exposure could be significantly higher among farmers, hunters, and fishermen who frequent forested areas than other groups in the same locality. However, deer flies are known to bite long distances away from their breeding sites.

High vector densities are known to be associated with high intensity of transmission, human infection, and disease rates [30]. In this study ABR correlated positively with ATP, indicating that intense vector biting led to high transmission intensity [28]. Biting was lowest in December and incidentally no infective fly was collected in that month which is suggestive of zero transmission. The ATP is a measure of exposure to infective biting or the force of infection [31]. Chrysops do have a low infectivity potential in the Nigerian environment [32]. Higher proportion of parous Chrysops during the dry season months could be due to relatively less recruitment of new nulliparous as a result of relatively unfavorable condition of breeding sites, possible drying up of oviposition sites, and higher rate of desiccation during this time.

A previous study in the study area reported a prevalence of Loiasis microfilaraemia to be $10.8 \%$ [2]. It is noteworthy that the incidence of detectable filariasis does not represent current exposure, but is generally the result of many years of exposure [33].

In conclusion, the epidemiological implications of deer fly biting in the area are multifaceted. Firstly, deer flies are vicious biters that cause intense pain at the site of the bite, which is very annoying to livestock as well as to people [34]. The adult flies are very strong fliers traveling long distances from breeding sites thereby constituting nuisance to most inhabitants of affected communities [34]. Their biting affects the human population in their various occupations, but is more intense among occupations that take individuals to the wetlands, streams, and rivers. Deer flies zoom in quickly on their hosts, circle fast, and bite quickly [34]. This intense biting results not only in the transmission of Loiasis but also in incessant distractions at workplaces leading to colossal loss of invaluable man-hours, and the consequent development of pathology.
This study indicated an intense and sustained on-going transmission of Loiasis in the Imo River Basin. Being the first study to evaluate the biting and transmission indices of deer flies in Nigeria, this work provides health authorities and planners with the quantitative data and the hard evidence of sustained transmission of Loiasis in the area and advocates the urgent need to commence mitigation measures against deer fly biting in the area. Although there are no satisfactory methods for control of deer flies as it is impracticable in most regions to eliminate their breeding areas, especially along endangered wetlands and watercourses where these flies are commonly found, clearing of the vegetation and the use of fly traps, which reduces the vector population, must be encouraged. Larval control is equally impracticable, especially in recreation areas or water reservoirs. The use of broad-spectrum insecticides to target the adults should be avoided as these substances could be toxic to fish, birds, and mammals. Traditional repellants are available but not effective in keeping away deer flies. Repellants containing DEET (N-diethyl-meta-toluamide) do not prevent flies from landing, but may inhibit most of the flies from biting. However, some of the repellants must be used with caution as some are harmful to man. To reduce exposure to bites, it is best to wear light-colored clothing, especially on warm, sunny days when deer flies are most active. Avoidance of heavy biting areas may be the best preventive strategy against this menacing vector. In the same vein, avoidance of the peak biting periods would translate to escaping $51 \%$ of the biting by deer fly in the Imo River Basin as discovered in this study. Deer flies are of immense economic importance in the Imo River Basin area; awareness campaigns detailing vector avoidance strategies must be emphasized, and resources must not be spared in combating them and bringing an end to their incredible menace.

\section{Conflict of Interests}

The author declares there is no conflict of interests.

\section{Acknowledgments}

The contributions of the vector collecting team, the village heads, and the village health supervisors are all appreciated.

\section{References}

[1] A. Fain, "Epidemiologie et pathologie de la loase," Annales de la Société Belge de Médecine Tropicale, vol. 61, pp. 277-285, 1981.

[2] E. C. Uttah, P. E. Simonsen, E. M. Pedersen, and J. K. Udonsi, "Loaiasis in the Upper Imo River Basin, Nigeria," Global Journal of Pure and Applied Sciences, vol. 11, no. 4, pp. 471-476, 2005.

[3] D. Heyneman, "Medical pareasitology," in Medical Microbiology, G. F. Brooks, J. S. Butyel, and S. A. Morse, Eds., pp. 661-701, McGraw Hill, Boston, Mass, USA, 23rd edition, 2004.

[4] F. Hawking, "The distribution of human filariasis throughout the world-part III. Africa," Tropical Diseases Bulletin, vol. 74, no. 8, pp. 649-679, 1977.

[5] E. O. Ogunba, "Loiasis in Ijebu Division, West Nigeria," Tropical and Geographical Medicine, vol. 23, no. 2, pp. 194-200, 1971. 
[6] E. O. Ogunba, "Ecology of human loiasis in Nigeria," Transactions of the Royal Society of Tropical Medicine and Hygiene, vol. 66, no. 5, pp. 743-748, 1972.

[7] J. P. O. Oyerinde, T. Odugbemi, and A. F. Fagbenro-Beyioku, "Investigations of filarial worms of man in metropolitan Lagos. Short communication," Acta Tropica, vol. 45, no. 2, pp. 191-192, 1988.

[8] O. M. Agbolade and D. O. Akinboye, "Loa loa and Mansonella perstans infections in Ijebu north, western Nigeria: a parasitological study," Japanese Journal of Infectious Diseases, vol. 54, no. 3, pp. 108-110, 2001.

[9] D. O. Akinboye and A. F. Ogunrinade, "Malaria and loaisis among blood donors at Ibadan, Nigeria," Transactions of the Royal Society of Tropical Medicine and Hygiene, vol. 81, no. 3, pp. 398-399, 1987.

[10] G. O. Ufomadu, G. O. C. Ekejindu, I. Tada, K. Shiwaku, and B. E. B. Nwoke, "Acid phosphatase variation in microfilariae of Dipetalonema perstans and Loa loa from Jos Plateau, Nigeria," Japanese Journal of Parasitology, vol. 82, pp. 75-82, 1986.

[11] G. O. Ufomadu, B. E. B. Nwoke, J. I. Akoh et al., "The occurrence of loiasis, mansonellosis and wuchereriasis in the Jarawa River Valley, Central Nigeria," Acta Tropica, vol. 48, no. 2, pp. 137-147, 1990.

[12] O. B. Akogun, "Filariasis in Gongola State Nigeria-I: clinical and parasitological studies in Mutum-Biyu District," Angewandte Parasitologie, vol. 33, no. 3, pp. 125-131, 1992.

[13] J. C. Anosike, "The status of human filariasis in north-western zone of Bauchi State, Nigeria," Applied Parasitology, vol. 35, no. 2, pp. 133-140, 1994.

[14] I. Takougang, M. Meremikwu, S. Wandji et al., "Rapid assessment method for prevalence and intensity of Loa loa infection," Bulletin of the World Health Organization, vol. 80, no. 11, pp. 852-858, 2002.

[15] J. K. Udonsi, "Filariasis in the Igwun River Basin, Nigeria: an epidemiological and clinical study with a note on the vectors," Annals of Tropical Medicine and Parasitology, vol. 82, no. 1, pp. 75-82, 1988.

[16] J. C. Anosike, B. E. B. Nwoke, C. O. E. Onwuliri et al., "Prevalence of parasitic diseases among nomadic Fulanis of southeastern Nigeria," Annals of Agricultural and Environmental Medicine, vol. 11, no. 2, pp. 221-225, 2004.

[17] B. O. DUKE, "Studies on the biting habits of Chrysops. VI. A comparison of the biting habits, monthly biting densities and infection rates of C. silacea and C. dimidiata (Bombe form) in the rain-forest at Kumba, Southern Cameroons, U.U.K.A," Annals of Tropical Medicine and Parasitology, vol. 53, pp. 203-214, 1959.

[18] M. Ovazza, J. Mouchet, and A. Rickenback, “Tabanidae du Cameroun-II. Les espéces connues et leur répartition," Cahiers O.R.S.T.O.M. Série Entomologie Médicale et Parasitologie, vol. 8, no. $4,1970$.

[19] F. Noireau, N. Albert, S. Dominique, and I. Andre, "Chrysops silacea and C. dimidiata: fly densities and infection rates with Loa loa in the Chaillu mountains, Congo Republic," Transactions of the Royal Society of Tropical Medicine and Hygiene, vol. 84, no. 1, pp. 153-155, 1990.

[20] S. Wanji, N. Tendongfor, M. Esum, S. N. Atanga, and P. Enyong, "Heterogeneity in the prevalence and intensity of Ioiasis in five contrasting bioecological zones in Cameroon," Transactions of the Royal Society of Tropical Medicine and Hygiene, vol. 97, no. 2, pp. 182-187, 2003.
[21] I. A. Animashaun, "Environment and development: a general perspective," in Environment and Development in Nigeria, J. U. Obot, I. A. Animashaun, and E. A. Fayose, Eds., p. 201, Double Diamond, Port-Harcourt, Nigeria, 2002.

[22] H. Oldroyd, The Horse-Flies (Diptera: Tabanidae) of the Ethiopian Region, vol. 3, William Clowes and Sons, Ltd., London, UK, 1957.

[23] T. Q. Hoc and T. J. Wilkes, "The ovarioles structure of Anopheles gambiae (Diptera: Culicidae) and its use in determining physiological age," Bulletin of Entomological Research, vol. 85, pp. 56-69, 1995.

[24] J. F. Walsh, J. B. Davies, R. Le Berre, and R. Garms, "Standardization of criteria for assessing the effect of Simulium control in onchocerciasis control programmes," Transactions of the Royal Society of Tropical Medicine and Hygiene, vol. 72, no. 6, pp. 675-676, 1978.

[25] K. N. Opara, L. P. Usip, and E. E. Akpabio, “Transmission dynamics of Simulium damnosum in rural communities of Akwa Ibom State, Nigeria," Journal of Vector Borne Diseases, vol. 45, no. 3, pp. 225-230, 2008.

[26] R. M. Gordon, W. E. Kershaw, W. Crewe, and H. Oldroyd, "Paper: the problem of loiasis in West Africa with special reference to recent investigations at Kumba in the British Cameroons and at Sapele in Southern Nigeria," Transactions of the Royal Society of Tropical Medicine and Hygiene, vol. 44, no. 1, pp. 11-47, 1950.

[27] M. F. Bowen, "The sensory physiology of host-seeking behavior in mosquitoes," Annual Review of Entomology, vol. 36, pp. 139-158, 1991.

[28] M. J. Lehane, Biology of Blood-Sucking Insects, Harper Collins Academic, London, UK, 1991.

[29] R. T. Rwegoshora, P. E. Simonsen, D. W. Meyrowitsch, M. N. Malecela-Lazaro, E. Michael, and E. M. Pedersen, "Bancroftian filariasis: house-to-house variation in the vectors and transmission - and the relationship to human infection-in an endemic community of coastal Tanzania," Annals of Tropical Medicine and Parasitology, vol. 101, no. 1, pp. 51-60, 2007.

[30] E. C. Uttah and D. C. Ibeh, "Multiple filarial species microfilaraemia: a comparative study of areas with endemic and sporadic onchocerciasis," Journal of Vector Borne Diseases, vol. 48, no. 4, pp. 197-204, 2011.

[31] P. E. Simonsen, D. W. Meyrowitsch, W. G. Jaoko et al., "Bancroftian filariasis infection, disease, and specific antibody response patterns in a high and a low endemicity community in East Africa," American Journal of Tropical Medicine and Hygiene, vol. 66, no. 5, pp. 550-559, 2002.

[32] S. D. S. Pion, M. Demanou, B. Oudin, and M. Boussinesq, "Loiasis: the individual factors associated with the presence of microfilaraemia," Annals of Tropical Medicine and Parasitology, vol. 99, no. 5, pp. 491-500, 2005.

[33] E. O. Ogunba, "Loa loa microfilaremia in the Nigerian population," Tropical and Geographical Medicine, vol. 29, no. 1, pp. 51-55, 1977.

[34] J. H. Klotz, S. A. Klotz, and J. L. Pinnas, "Animal bites and stings with anaphylactic potential," Journal of Emergency Medicine, vol. 36, no. 2, pp. 148-156, 2009. 


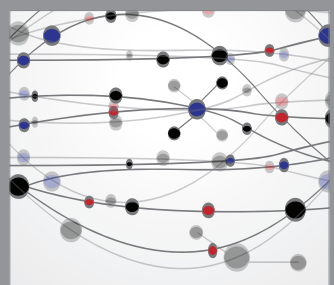

The Scientific World Journal
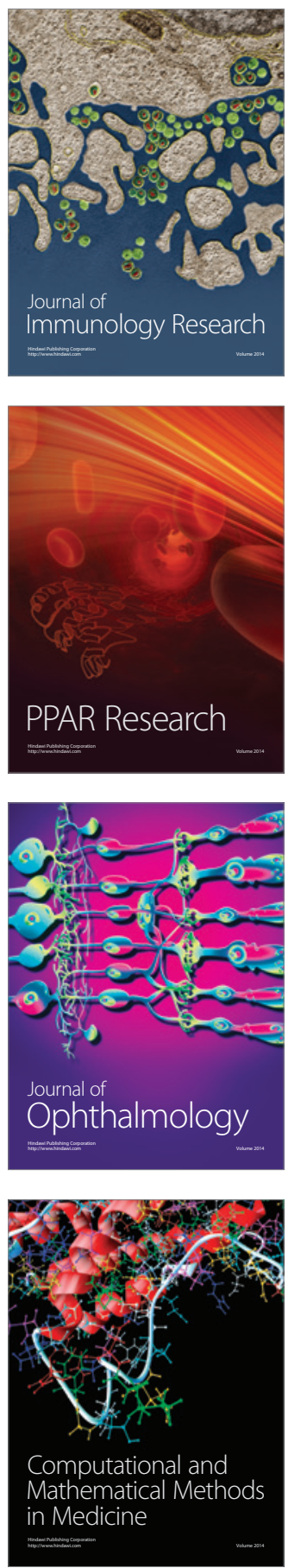

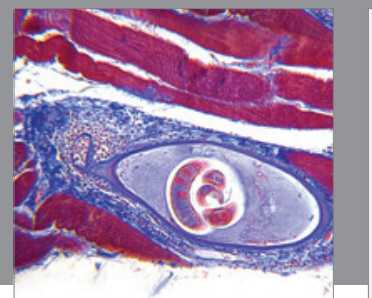

Gastroenterology

Research and Practice
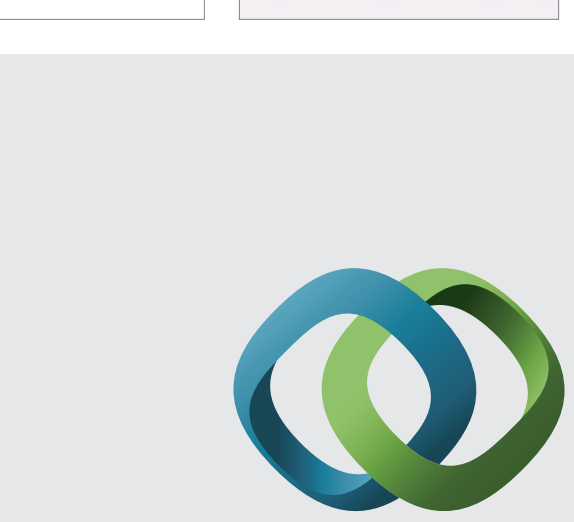

\section{Hindawi}

Submit your manuscripts at

http://www.hindawi.com
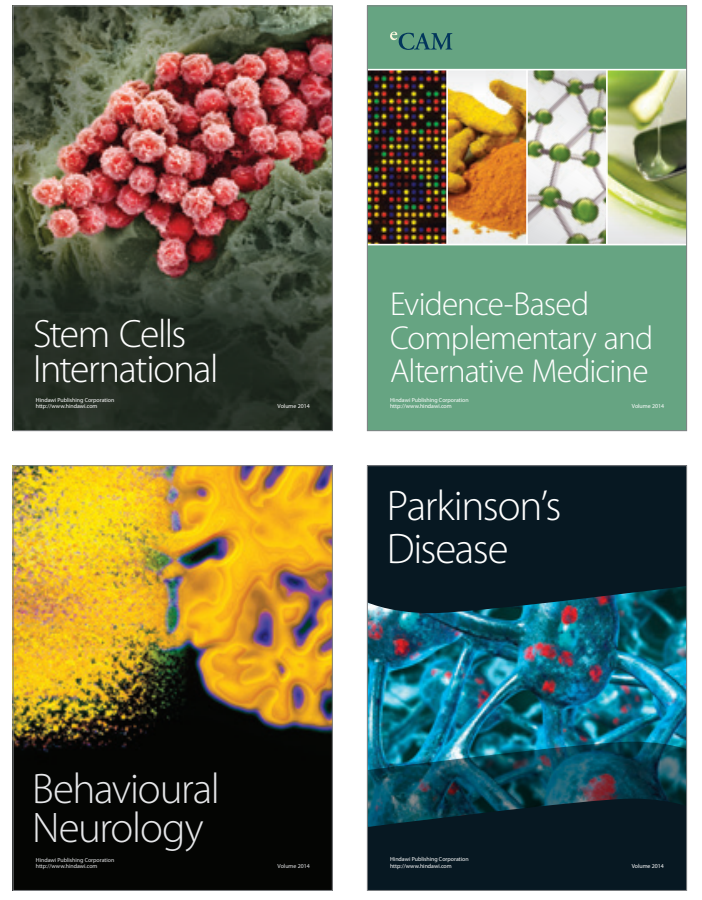
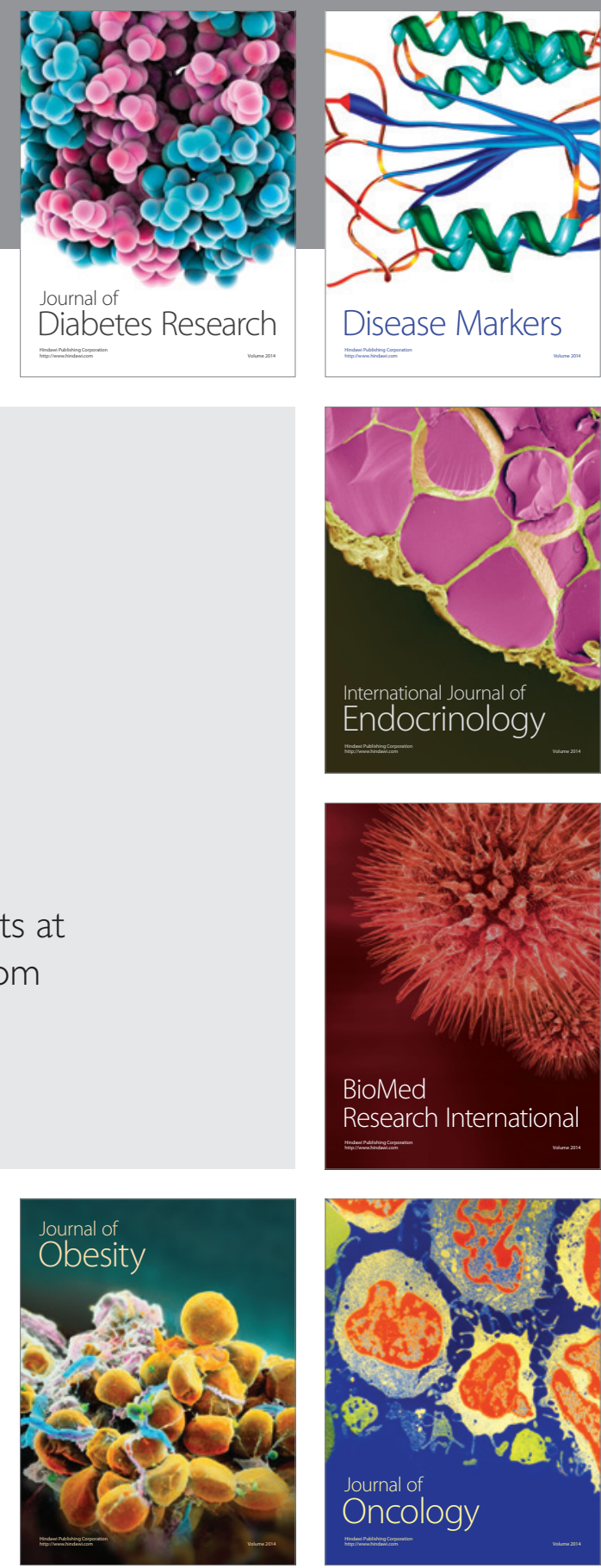

Disease Markers
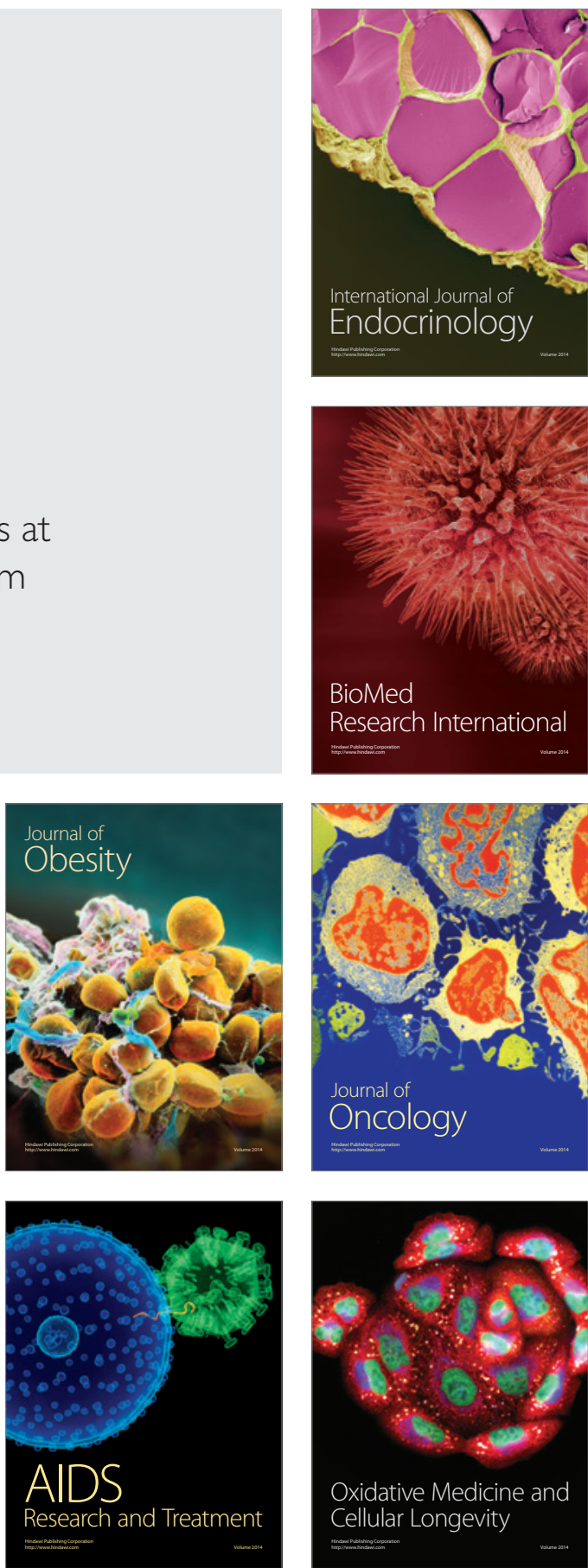